Sara Moitinho da Silva

\title{
A Criança Negra no Cotidiano Escolar
}

\author{
DISSERTAÇÃO DE MESTRADO
}

\author{
DEPARTAMENTO DE EDUCAÇÃO \\ Programa de Pós-Graduação em \\ Educação
}

Rio de Janeiro, março de 2009 


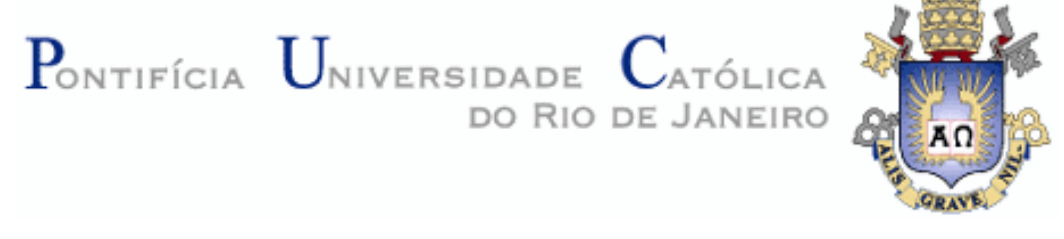

Sara Moitinho da Silva

A Criança Negra no Cotidiano Escolar

Dissertação de Mestrado

Dissertação apresentada ao Programa de Pós - Graduação em Educação da PUC - Rio como requisito parcial para a obtenção do título de Mestre em Educação.

Orientadora: Prof. ${ }^{a}$ Vera Maria Ferrão Candau 


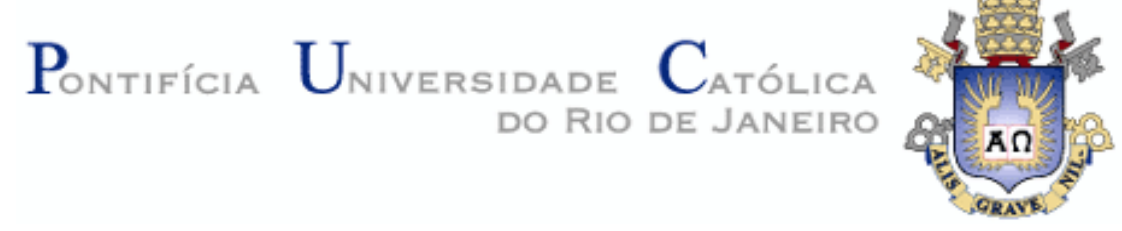

Sara Moitinho da Silva

\title{
A CRIANÇA NEGRA NO COTIDIANO ESCOLAR
}

Dissertação apresentada como requisito parcial para obtenção do grau de Mestre pelo Programa de Pósgraduação em Educação do Departamento de Educação do Centro de Teologia e Ciências Humanas da PUC Rio. Aprovada pela Comissão Examinadora abaixo assinada.

\author{
Prof'. Vera Maria Ferrão Candau \\ Orientadora \\ Departamento de Educação PUC - Rio
}

Prof. Marcelo Andrade

Departamento de Educação - PUC- Rio

Patrícia Corsino

UFRJ

Prof. Paulo Fernando Carneiro de Andrade

Coordenador Setorial do Centro de Teologia e Ciências Humanas

PUC - Rio

Rio de Janeiro, 
Todos os direitos reservados. É proibida a reprodução total ou parcial do trabalho sem autorização da universidade, da autora e do orientador.

\section{Sara Moitinho da Silva}

Licenciada em Pedagogia - Magistério da Disciplinas Pedagógicas do $2^{\circ}$ Grau - em 1999; especializou-se em Alfabetização das Crianças das Classes Populares, em 2001 pela Universidade Federal Fluminense - UFF. Atualmente participa do grupo de pesquisa GECEC - Grupo de Estudos sobre Cotidiano, Educação e Cultura(s) do Departamento de Educação da PUC - Rio, coordenado pela professora Vera Maria Candau.

Ficha Catalográfica

Silva, Sara Moitinho da

A criança negra no cotidiano escolar / Sara Moitinho da Silva; orientadora: Vera Maria Ferrão Candau. - 2009.

161 f. ; il. ; $30 \mathrm{~cm}$

Dissertação (Mestrado em Educação)-Pontifícia

Universidade Católica do Rio de Janeiro, Rio de Janeiro, 2009.

Inclui bibliografia

1. Educação - Teses. 2. Crianças negras. 3. Perspectiva multicultural e intercultural. 4. Relações étnico-raciais. 5. Cotidiano escolar. I. Candau, Vera Maria Ferrão. II. Pontifícia Universidade Católica do Rio de Janeiro. Departamento de Educação. III. Título. 


\section{Dedicatória}

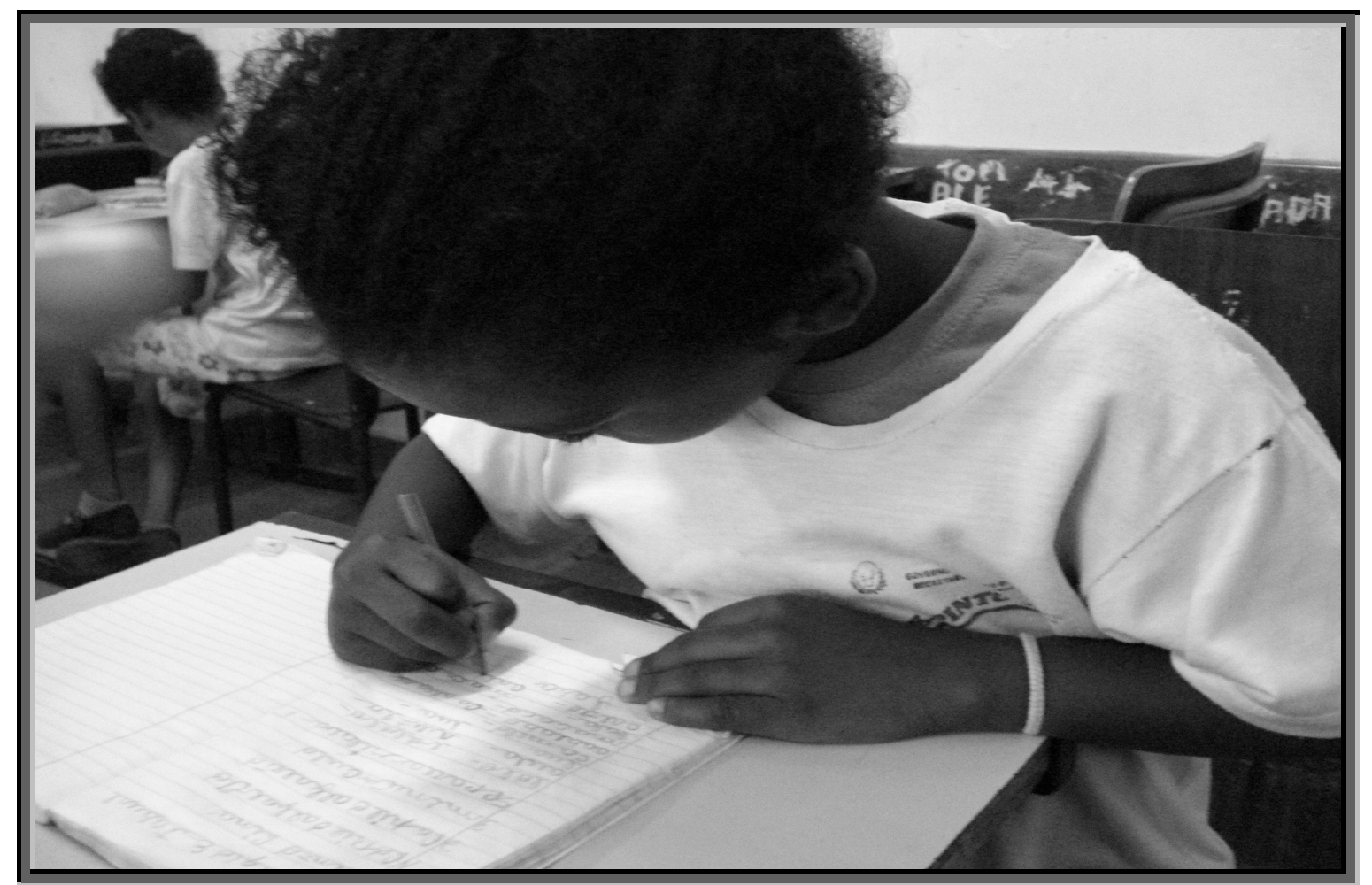

Foto 1: Menina negra na sala de aula fazendo uma atividade.

Ao meu Deus, que tem me dado sabedoria para a realização desse trabalho.

Para as crianças que participaram dessa pesquisa e que sempre me mostraram que é possível construir um mundo mais justo, humano e fraterno. 


\section{Agradecimentos}

Ao meu Deus, meu Jesus Cristo, por todas as coisas que tem me proporcionado, pelo cuidado, carinho com minha vida, em todos os momentos e em todas as horas. Muito Obrigada!

À minha orientadora, Vera Maria Candau, que acreditou e confiou na construção do trabalho; pela dedicação, paciência e incentivo para a finalização dessa dissertação.

Ao CNPq e à PUC - Rio, pelos auxílios concedidos, que me ajudaram para a realização dessa dissertação.

Às crianças da escola pesquisada, pelo carinho, atenção e compreensão para a realização dessa pesquisa. Foi fundamental o diálogo com as crianças para o desenvolvimento deste projeto. Tenho muito que agradecê-las, pelos diálogos constantes e pela confiança na pesquisadora!

Aos professores do curso de mestrado da PUC - Rio, que tanto contribuíram para a minha formação. Vocês foram fundamentais para a realização desse trabalho. Em especial a Aparecida Mamede, Isabel Lelis, José Mauricio, Maria Inês e Rosália.

Às coordenadoras da Pós-Graduação Rosália Duarte e Sônia Kramer e suas equipes, pela assistência e dedicação ao longo desse percurso de dois anos.

Aos diretores, professores e funcionários da escola, pelo carinho, confiança e disponibilidade para o desenvolvimento do meu projeto. Cheguei a essa escola sem conhecer nada e ninguém e fui muito bem recebida. Muito obrigada a todos!

Aos professores que integraram a comissão Examinadora.

A todos os integrantes do GECEC - Grupo de Estudos sobre Cotidiano, Educação e Cultura(s), da PUC- Rio, pela contribuição para a realização desse trabalho.

À Adélia pelo carinho, incentivo e empenho para a finalização desse trabalho.

À minha mãe, Darci Moitinho, minha primeira professora, meu primeiro amor. Lembranças! Saudades! (em memória).

Ao meu pai, João, meu primeiro orientador. Saudades! (em memória)

Ao meu querido Bel, pela paciência, pelo carinho e muita compreensão pelos tantos momentos ausentes que não pude estar tão presente durante o processo dessa dissertação. Obrigada pelo amor, incentivo e muita dedicação.

A todos os amigos e familiares que torceram por mim ao longo deste percurso. 


\section{Resumo}

Moitinho, Sara; Candau, Vera Maria Ferrão. A Criança Negra no Cotidiano Escolar. Rio de Janeiro, 2009. 161p. Dissertação de Mestrado - Departamento de Educação, Pontifícia Universidade Católica do Rio de Janeiro.

A presente dissertação tem como objetivo conhecer e compreender as relações das crianças negras no cotidiano escolar de uma escola pública do município de Niterói. O principal referencial teórico utilizado foram os estudos sobre multiculturalismo e interculturalismo, assim como as pesquisas realizadas sobre relações étnicorraciais na escola, focando as crianças negras. Para a análise do estudo etnográfico, foram utilizados autores do campo da antropologia e dos estudos sobre sociologia da infância e da criança. A pesquisa de campo, de caráter qualitativo e inspiração etnográfica, foi realizada no primeiro semestre de 2008 e supôs observações sistemáticas no cotidiano de uma sala de aula, quatro dias na semana, durante cinco meses, assim de diferentes espaços escolares - corredor, recreio, refeitório, entrada e saída, etc-, assim como entrevistas com membros do corpo docente da escola e diálogos informais com as crianças. A turma estava formada por 28 crianças, de faixa etária de 7 a 14 anos, do $1^{\mathrm{a}}$ ano do Ensino Fundamental.

\section{Palavras-chave}

Crianças negras; Perspectiva multicultural e intercultural; Relações étnicorraciais; Cotidiano escolar. 
Abstract

Moitinho, Sara; Candau, Vera Maria Ferrão (Advisor). The Black Child in Daily

School Life. Rio de Janeiro, 2009. 161p. Master's Dissertation - Education Departament, Catholic University, Rio de Janeiro.

This dissertation aims at knowing and understanding the relations of black children in daily school life in a public school in the municipality of Niterói. The main theoretical references used were the multicultural and intercultural studies carried out, as well as research regarding ethnic-racial relations within the school, with a focus on black children. For the analysis of the ethnographic study, authors in the fields of anthropology and child sociology as well as sociological studies on childhood were chosen. The field research, with a qualitative approach and ethnographic nature, was conducted in the first semester of 2008 , by daily systematic observations of a class room, four days a week, during five months, and also of other school areas, such as hall, recreational area, cafeteria, entrance and exit gates, etc., as well as via interviews with school faculty members and informal dialogues with the children. The class was composed by 28 students, between the ages of 7 and 14, of the first year of elementary school.

\section{Keywords}

Black Children; multiculturalism and intercuturalism perspective; ethnicracial relations; daily school life. 


\section{Sumário}

1 Introdução 12

2 A Perspectiva multi/intercultural e suas contribuições para a educação das relações etnicorraciais

2.1 Educação, multiculturalismo e a perspectiva intercultural

2.2 Relações raciais e cotidianas escolar: o que dizem as pesquisas

2.3 As contribuições da Lei 10.639/0340

3 Estratégias metodológicas - Os caminhos percorridos

3.1 A entrada no campo

3.2 A abordagem etnográfica e suas contribuições para a pesquisa com crianças

3.3 A coleta de dados: os instrumentos utilizados 58

3.3.1 A observação participante $\quad 59$

$\begin{array}{ll}\text { 3.3.2 As entrevistas } & 61\end{array}$

3.3.3 O registro fotográfico 64

3.3.4 O desenho da criança 66

4 "A nossa escola é uma escola que atende crianças moradoras $\begin{array}{ll}\text { de favelas e em sua maioria crianças negras" } & 68\end{array}$

$\begin{array}{lll}4.1 & \text { Contextualizando a escola } & 68\end{array}$

4.1.1 A escola Boa Vista $\quad 69$

4.1.2 O pátio da escola Boa Vista e seus rituais 72

$\begin{array}{ll}\text { 4.1.3 A sala de aula é um mundo social } & 78\end{array}$

$\begin{array}{ll}\text { 4.1.4 O refeitório e as crianças } & 81\end{array}$ 
5 "O que você está fazendo aqui na nossa sala de aula?"

"Ela está escrevendo sobre a nossa vida" 86

5.1 Conhecendo as crianças, suas vidas e suas relações 87

5.1.1 Perfil social das crianças que participaram da pesquisa 88

5.1.2 A autodeclaração realizada pelas crianças e seus desenhos 96

$\begin{array}{lll}5.2 & \text { Histórias sobre a vida das crianças } & 107\end{array}$

5. 2. 1 A história de Letícia 108

5. 2. 2 A história do José 109

5. 2. 3 A história do Victor 111

5. 2. 4 A história da Tereza 113

6 "Aqui na escola a grande maioria é de negros e da favela" 119

$\begin{array}{lll}6.1 & \text { Trajetória profissional e experiência das professoras } & 119\end{array}$

6.2 Os principais desafios declarados pelas professoras 122

$\begin{array}{ll}6.3 & \text { As crianças que frequentam a escola } \\ 6\end{array}$

6.4 Conflitos, preconceitos e discriminação e racismo no
cotidiano escolar

$7 \quad$ Considerações Finais 142

8 Referências Bibliográficas $\quad 149$

Anexo 1: Ficha 158

Anexo 2: Roteiro das entrevistas com as professoras 159

Anexo3: Roteiro das entrevistas com coordenadora e diretora 160 


\section{Lista de Figuras}

Figura 1 - Uma menina negra na sala de aula fazendo uma atividade proposta pela professora da turma

Figura 2 - A entrada da escola

Figura 3 - Os meninos e as meninas aguardando o portão da escola abrir

Figura 4 - Uma menina produzindo um desenho em sala de aula

Figura 5 - Uma menina negra desenhando sua casa

Figura 6 - O Prédio da Escola Estadual Boa Vista

Figura 7 - Pátio Coberto da Escola 70

Figura 8 - Pátio Descoberto da Escola 70

Figura 9 - Primeiro corredor da escola

Figura 10 - Meninos e meninas entrando no pátio coberto para se organizarem em filas

Figura 11 - Crianças brincando no pátio coberto no recreio

Figura 12 - A sala de aula

Figura 13 - Crianças no refeitório da escola

Figura 14 - O refeitório da escola

Figura 15 - O desenho da Lara e seu texto sobre sua vida

Figura 16 - O desenho da Ana Carla

103

Figura 17 - O desenho do Rodolfo

Figura 18 - O desenho do Juca

Figura 19 - O desenho do Victor 


\section{Epígrafe}

Os "outros", os diferentes, muitas das vezes estão perto de nós, e mesmo dentro de nós, mas não estamos acostumados a vê-los, ouvi-los, reconhecê-los, valorizálos e interagir com eles. Na sociedade em que vivemos há uma dinâmica de construção de situações de apartação social e cultural que confinam os diferentes grupos sócioculturais em espaços diferenciados, onde somente os considerados iguais têm acesso. Ao mesmo tempo, multiplicam-se as grades, os muros, as distâncias, não somente físicas, como também afetivas e simbólicas entre pessoas e grupos cujas identidades culturais se diferenciam por questões de pertencimento social, étnico, de gênero, religioso, etc (CANDAU, 2008, p. 31). 